\title{
Progesterone-regulated Hsd11b2 as a barrier to balance mouse uterine corticosterone
}

\author{
Hong-Tao Zheng, Tao Fu, Hai-Yi Zhang, Zhen-Shan Yang, Zhan-Hong Zheng and Zeng-Ming Yang \\ College of Veterinary Medicine, South China Agricultural University, Guangzhou, China \\ Correspondence should be addressed to Z-M Yang: zmyang@scau.edu.cn
}

\begin{abstract}
Glucocorticoids (GCs) are essential for mouse embryo implantation and decidualization. Excess GCs are harmful for mouse embryo implantation and decidualization.

11ß-Hydroxysteroid dehydrogenases type I and II (Hsd11b1/Hsd11b2) are main enzymes for regulating local level of GCs. Hsd11b2 acts as the placental glucocorticoid barrier to protect the fetus from excessive exposure. Although effects of GCs on the fetus and placenta in late pregnancy have been extensively studied, the effects of these adrenal corticosteroids in early pregnancy are far less well defined. Therefore, we examined the expression, regulation and function of Hsd $11 \mathrm{~b} 1 / \mathrm{Hsd} 11 \mathrm{~b} 2$ in mouse uterus during early pregnancy. We found that Hsd1 $1 \mathrm{~b} 2$ is highly expressed in endometrial stromal cells on days 3 and 4 of pregnancy and mainly upregulated by progesterone (P4). In both ovariectomized mice and cultured stromal cells, P4 significantly stimulates Hsd11 b2 expression. P4 stimulation of Hsd11b2 is mainly mediated by the Ihh pathway. The uterine level of corticosterone (Cort) is regulated by Hsd11 b2 during preimplantation. Embryo development and the number of inner cell mass cells are suppressed by Cort treatment. These results indicate that P4 should provide a low Cort environment for the development of preimplantation mouse embryos by promoting the expression of uterine Hsd1 $1 \mathrm{~b} 2$.
\end{abstract}

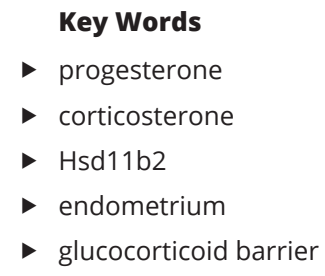

Journal of Endocrinology (2020) 244, 177-187

\section{Introduction}

Uterine receptivity and decidualization are critical events for the success of pregnancy in mice and humans (Dey et al. 2004, Cha et al. 2012). P4 is necessary for the establishment and maintenance of pregnancy in almost all mammals (Tu et al. 2014). P4 acts mainly through intracellular progesterone receptor (PGR). PGR-deficient mice are infertile (Lydon et al. 1995, Bhurke et al. 2016).

Ihh, a member of the hedgehog gene family, is a secretory protein regulated by $\mathrm{P} 4$ and expressed in the uterine epithelium during preimplantation (Bhurke et al. 2016). Epithelial Ihh triggers the recruitment and activation of the intracellular transducer Smoothened by binding to its receptor Patched (Ptc) in stromal cells (McMahon 2000). These signaling events activate the downstream transcription factors Gli1-3 and chicken ovalbumin upstream promoter-transcription factor II (COUP-TFII), which regulate cell proliferation and differentiation (Bhurke et al. 2016). Uterine epitheliumspecific deletion of PGR shows reduced expression of Ihh with loss of epithelial PGR (Franco et al. 2012). Uterinespecific deletion of Ihh leads to infertility due to a defect in embryo implantation (Lee et al. 2006). Further studies show that loss of epithelial Ihh is also associated with aberrant gene expression in the stroma, suggesting that Ihh regulates stromal function via paracrine mechanisms 
(Kurihara et al. 2007, Bhurke et al. 2016). These results indicate that the PGR-Ihh signaling pathway mediates epithelial-stromal interaction in the endometrium.

GCs, steroid hormones released by the adrenal cortex, are involved in the establishment and maintenance of pregnancy in mice (Whirledge et al. 2015). However, accumulating evidence suggests that exposure to high levels of GCs during pregnancy is detrimental for both embryo implantation and fetal development (Seckl \& Meaney 2004, Zhao et al. 2013, Jafari et al. 2017, Li et al. 2018). Hsd11b1/Hsd11b2 are main enzymes for regulating local level of GCs (cortisol in humans; corticosterone in mice). Hsd11b1 catalyzes the conversion of inactive cortisone and 11-dehydrocorticosterone into active cortisol and corticosterone, respectively. In contrast, Hsd11b2 catalyzes the conversion of active cortisol and corticosterone into inactive cortisone and 11-dehydrocorticosterone, respectively (Sandeep \& Walker 2001). Hsd11b2, as the placental GC barrier, is mainly located in the syncytial layer of the placental villi to protect the fetus from excessive cortisol or corticosterone exposure (Togher et al. 2014, Zhu et al. 2019). Fetal GC levels are lower than maternal levels (Beitins et al. 1973, Seckl \& Walker 2001). Reduced placental Hsd11b2 activity and mRNA are observed in a subgroup of fetuses with intrauterine growth restriction (Dy et al. 2008). Both chronic restraint stress and feed restriction cause an increase in maternal Cort levels and reduced placental Hsd11b2 mRNA expression, which result in lower fetal birth weight in pregnant rats (Togher et al. 2014). This evidence indicates that placental Hsd11b2 plays a major role during pregnancy when the fetus is exposed to maternal GCs. However, whether there is a uterine GC barrier before placentation is largely unknown. GCs are used to treat infertile patients with repeated IVF failure and recurrent miscarriage (Boomsma et al. 2012). It seems that the fertility-promoting or -inhibiting effects of GCs are dependent on timing, dose, and responsiveness within a given tissue (Robertson et al. 2016). Although effects of GCs on the fetus and placenta in late pregnancy have been extensively studied, the effects of these adrenal corticosteroids in early pregnancy are far less well defined.

To address this issue, we examined the spatiotemporal expression and function of $\mathrm{Hsd} 11 \mathrm{~b} 2$ during early pregnancy. Our data showed that uterine Hsd11b2 plays an important role in maintaining GC balance during preimplantation.

\section{Materials and methods}

\section{Animals and treatments}

All animal experiments were approved by the Animal Care and Use Committee of South China Agricultural University. All CD1 mice were housed in a controlled environment with a $14 \mathrm{~h}$ light: $10 \mathrm{~h}$ dark cycle. Female mice, aged 8-10 weeks, were mated with fertile or vasectomized males to induce pregnancy or pseudopregnancy (day 1 is the day of vaginal plug). From days 1 to 4 , pregnancy was confirmed by flushing the embryos from the oviducts or uteri.

Ovariectomized mice were used to examine the effects of P4 following 2 weeks of recovery. The ovariectomized mice received a single s.c. injection of P4 ( $1 \mathrm{mg} / \mathrm{mouse}$, Sigma-Aldrich). The control mice received vehicle (sesame oil, $0.1 \mathrm{~mL} /$ mouse) only. Mice were killed to collect uteri at different time points after P4 injections. RU486, an antagonist of PGR, was subcutaneously injected $(8 \mathrm{mg} / \mathrm{kg}$ body weight, Cayman Chemical) to examine PGR involvement of $\mathrm{P} 4$ regulation (Cheon et al. 2002). The control mice received vehicle (sesame oil, $0.1 \mathrm{~mL} /$ mouse) only. Mice were killed $24 \mathrm{~h}$ later to collect uteri.

To examine the effects of P4 on Cort level in uterine lumen fluid, ovariectomized mice received a single s.c. injection of vehicle (sesame oil, $0.1 \mathrm{~mL} /$ mouse) or $\mathrm{P} 4$ (1 mg/mouse). After $12 \mathrm{~h}$ of injection, ovariectomized mice received a single s.c. injection of vehicle (DMSO, $0.1 \mathrm{~mL} / \mathrm{mouse}$ ) or Cort (1 mg/mouse, Cayman Chemical). Mice were killed $3 \mathrm{~h}$ later to collect the fluid from uterine lumen.

Single prolonged stress (SPS) tests were performed as previously described (Deslauriers et al. 2018). Briefly, ovariectomized mice underwent a restraintimmobilization stress test for $2 \mathrm{~h}$ and forced swimming for $20 \mathrm{~min}$ in $24^{\circ} \mathrm{C}$ water. They were allowed to recuperate for $15 \mathrm{~min}$. Finally, the mice were exposed to diethyl ether until loss of consciousness. To compare with SPS, ovariectomized mice were intraperitoneally injected with Cort ( $1 \mathrm{mg} /$ mouse in $0.1 \mathrm{~mL}$ DMSO). The control mice were intraperitoneally injected with $0.1 \mathrm{~mL}$ DMSO. Mouse serum was collected $1 \mathrm{~h}$ after SPS or Cort injection. Uterine segments were collected $6 \mathrm{~h}$ after SPS or Cort injection.

\section{In situ hybridization}

Total RNAs from mouse kidneys were reverse-transcribed, and each template of hybridization probe was amplified https://joe.bioscientifica.com https://doi.org/10.1530/JOE-19-0349 (c) 2020 Society for Endocrinology Published by Bioscientifica Ltd. Printed in Great Britain 
Table 1 Primers used in this study.

\begin{tabular}{lll}
\hline Gene & ID & Application \\
\cline { 1 - 1 } Rpl7 & M29016 & RT-PCR \\
Hsd11b1 & NM_008288.2 & ISH \\
Hsd11b2 & NM_008289.2 & ISH \\
Hsd11b1 & NM_008288.2 & RT-PCR \\
Hsd11b2 & NM_008289.2 & RT-PCR \\
Ihh & NM_001313683.1 & RT-PCR \\
Dhh & NM_007857.5 & RT-PCR \\
Shh & NM_009170.3 & RT-PCR \\
Gli1 & NM_010296.2 & RT-PCR \\
Gli2 & NM_001081125.1 & RT-PCR \\
Gli3 & NM_008130.3 & RT-PCR \\
\hline
\end{tabular}

\begin{tabular}{l}
\hline Primers $\left(5^{\prime}{ }^{\prime}{ }^{\prime}\right)$ \\
\hline GCAGATGTACCGCACTGAGATTC \\
ACCTTTGGGCTTACTCCATTGATA \\
GCTGGCACTATGGAAGAC \\
CCTTGGTATGTAGAGTTCTG \\
TGTGAACCTCTGGGAGAAACG \\
CGGGGCAGAAGGTGATTG \\
CGACATCCACTCTGTGCGAA \\
TGCTGCCATTGCTCTGCT \\
TGTGAACCTCTGGGAGAAACG \\
GCATCTACAACTGGGCTAAGGT \\
CTGCGGTTCTGTCTGTTC \\
GTTCTCCTCGTCCTTGAAG \\
GACCGTGACCGTAATAAGTA \\
GACCGCCAGTGAGTTATC \\
CAGCGGCAGATATGAAGG \\
GAGACTCCTCTGAATGATGG \\
TTCATCAACTCTCGCTGTA \\
TTGCCAACCATCATATCCA \\
GTCACATCAGCCAACCAA \\
AGCCTCCATTCTGTTCATAC \\
CTGCGGTATCTCCTCTCA \\
TAGTGCTGGTATTGCTGTC
\end{tabular}

\begin{tabular}{|c|}
\hline Products (bp) \\
\hline 129 \\
\hline 349 \\
\hline 306 \\
\hline 101 \\
\hline 156 \\
\hline 261 \\
\hline 126 \\
\hline 242 \\
\hline 242 \\
\hline 163 \\
\hline 156 \\
\hline
\end{tabular}

with the corresponding primers (Table 1). pGEM-T vector plasmid (Promega) was used to clone the amplified fragments of different genes. Digoxigenin-labeled antisense or sense cRNA probes were transcribed in vitro by using a digoxigenin RNA labeling kit (Roche Diagnostics). In situ hybridization was performed as previously described (Lei et al. 2012, Ding et al. 2018).

\section{Real-time RT-PCR}

Total RNAs from mouse uteri or cultured cells were isolated using TRIzol reagent (TaKaRa, Tokyo, Japan), digested with RQ1 deoxyribonuclease I (Promega) and reverse transcribed into cDNA with a PrimeScript reverse transcriptase reagent kit (Vazyme, Najing, Jiangsu, China). cDNA was amplified using a SYBR Premix Ex Taq kit (Vazyme) on the BIORADCFX96 $^{\mathrm{TM}}$ Real-Time System (Bio-Rad) according to the manufacturer's recommendations. The specificity of each pair of primers for each gene was checked through the melting curve to make sure a single peak. All reactions were run in triplicate. All primer sequences used for realtime RT-PCR were listed in Table 1 . The real-time values are normalized to the RPL7 expression level and indicated as the mean \pm s.E.M.

\section{Western blot}

The uterine tissues were homogenized in lysis buffer (50 mM Tris- $\mathrm{HCl}, \mathrm{pH} 7.5,0.1 \%$ SDS, $150 \mathrm{mM} \mathrm{NaCl}$,

(C) 2020 Society for Endocrinology Published by Bioscientifica Ltd.
Printed in Great Britain
$1 \%$ Triton X-100, and $0.25 \%$ sodium deoxycholate) and supplemented with protease inhibitor cocktail (Roche) on ice. Cultured cells were scratched directly in lysis buffer. Protein concentration was measured with a bicinchoninic acid assay reagent kit (Applygen, Beijing, China). Protein samples were separated by SDS-PAGE and transferred onto PVDF membranes (Merck Millipore). After blocking in 5\% nonfat powdered milk (Tris-buffered saline containing $0.1 \%$ Tween-20) for $1 \mathrm{~h}$, membranes were incubated with each primary antibody overnight at $4^{\circ} \mathrm{C}$ as follows: antiHsd11b2 (Santa Cruz Biotechnology) and anti- $\alpha$-Tubulin (Cell Signaling Technology). Western blot was performed as previously described (Lei et al. 2012).

\section{Isolation and culture of endometrial stromal cells}

Mouse endometrial stromal cells were isolated as previously described (Lei et al. 2012). Briefly, uterine horns from day 4 pregnant mice were split longitudinally and digested in Hanks' balanced salt solution containing $1 \%$ trypsin (Ameresco, Solon, OH, USA) and $6 \mathrm{mg} / \mathrm{mL}$ dispase II (Roche). After removing luminal epithelial cells, the remaining uteri were incubated with $0.15 \mathrm{mg} / \mathrm{mL}$ collagenase I (Invitrogen). Primary endometrial stromal cells were plated onto culture plates. Cultured stromal cells were treated with P4, RU486, Cyclopamine (TargetMol, Shanghai, China), Purmorphamine (Selleck Chemicals), GANT61 (TargetMol) or Cort, respectively. The doses of reagents used for treating stromal cells were chosen based 
on previous publications (Wu et al. 2004, Mazumdar et al. 2011, Lei et al. 2012). Then cells were collected at different time points for further quantitative analysis by real-time RT-PCR.

\section{Explant culture}

The uterine explant culture was performed as previously described (Matsumoto et al. 2002). Briefly, uteri from day 4 pregnant mice were slit longitudinally from the mesometrial side and digested in Hanks' balanced salt solution containing 1\% trypsin. After removing luminal epithelial cells, the remaining uteri were cut into $1.5-2 \mathrm{~mm}$ long pieces. Individual pieces were incubated in DMEM containing 10\% FBS for $3 \mathrm{~h}$. After $3 \mathrm{~h}$ of incubation, uterine explants were placed in fresh medium with or without Ihh $(2 \mu \mathrm{g} / \mathrm{mL}$; R\&D Systems) and cultured for $48 \mathrm{~h}$. Uterine explants were collected for real-time RT-PCR analysis.

\section{Measurement of Cort level in uterine lumen fluid}

Concentrations of Cort were measured by Cort ELISA Kit (Cayman Chemical, Ann Arbor, MI) per manufacturer instructions. Uterine lumen fluid was collected directly by intraluminal infusion of $200 \mu \mathrm{L}$ of PBS. The uterine fluid was mixed with four-fold volume of dichloromethane and vortexed for $2 \mathrm{~min}$. The dichloromethane layer (lower layer) was transferred into a clean test tube with a liquid shifter. Cort in the samples was extracted with dichloromethane three times. After evaporating the methylene chloride under a gentle stream of nitrogen, the extracts were dissolved in ELISA Buffer and measured by the ELISA Kit.

\section{Embryo culture and immunofluorescence}

All two-cell embryos were obtained by flushing mouse oviducts in the morning on day 2 of pregnancy and washed four times in M2 medium (Sigma-Aldrich). All embryos were cultured in KSOM-AA medium (Merck Millipore) with or without Cort. Cort was dissolved in DMSO and diluted in KSOM-AA medium. The final concentrations of Cort were $0.1,1$ and $10 \mu \mathrm{M}$. The rates of blastocyst formation and hatching were examined. Embryos were collected for immunofluorescence at the blastocyst stage. Blastocysts were fixed in $4 \%$ paraformaldehyde for $1 \mathrm{~h}$, washed three times in washing buffer (PBS containing 0.1\% Tween20) and permeabilized with PBS containing 0.5\% Triton X-100 for 15 min. Embryos were blocked with 5\% donkey serum for $1 \mathrm{~h}$ at $37^{\circ} \mathrm{C}$ and incubated overnight with rabbit anti-mouse Oct4 (Abcam) at the appropriate dilutions at $4^{\circ} \mathrm{C}$. After washing in washing buffer, embryos were incubated with an anti-rabbit antibody-conjugated with Alexa Fluor 488 (Jackson ImmunoResearch). Then nuclei were stained with propidium iodide (Sigma-Aldrich). The fluorescence was visualized under Leica Laser Scanning Confocal Microscopy.

\section{Statistical analysis}

All the experiments were independently repeated at least three times. Data were processed using GraphPad Prism 6 Software and reported as the mean \pm s.E.M. Student's $t$-test was used for the comparison between two groups. For multiple comparisons, ANOVA with post hoc Tukey was used. Statistical significance is indicated by ${ }^{*} P<0.05$.

\section{Results}

\section{Hsd11b1/2 expression in mouse uteri during early pregnancy}

The local inter-conversion between inactive 11-dehydrocorticosterone and active Cort is regulated by Hsd11b1/2 in mice. To explore whether the local conversion was present in the mouse uterus during early pregnancy, in situ hybridization was performed to examine the localization of $H s d 11 b 1 / 2$ mRNA.

Our results showed no detectable Hsd11b1 signal from days 1 to 7 of pregnancy. A strong Hsd11b1 signal was detected in the secondary decidual zone on day 8 of pregnancy (Fig. 1A). Hsd11b2 signals were mainly seen in endometrial stromal cells from days 3 to 4 of pregnancy (Fig. 1A). On day 5, Hsd11b2 was weakly expressed in the primary decidual cells at implantation sites (Fig. 1A).

Data from real-time PCR also showed that $\mathrm{Hsd11b2}$ mRNA levels were upregulated significantly in uteri on days 3 and 4 compared to days 1 and 2 (Fig. 1B). The protein levels of Hsd11b2 on days 3 and 4 were also significantly higher than that on days 1 and 2 (Fig. 1C). Because Hsd11b1 expression was very low during preimplantation, we mainly focused on Hsd11b2.

\section{P4 regulation on Hsd11b2 expression in mouse uterus}

Our data showed that expression of Hsd11b2 was highest on days 3 and 4 during early pregnancy (Fig. 1). Moreover, P4 level also increased significantly during this period https://joe.bioscientifica.com https://doi.org/10.1530/JOE-19-0349
(C) 2020 Society for Endocrinology Published by Bioscientifica Ltd.
Printed in Great Britain 
A
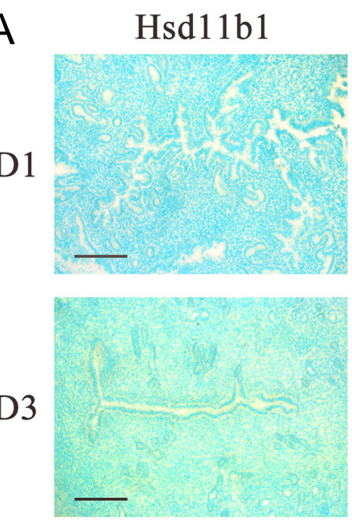

D4

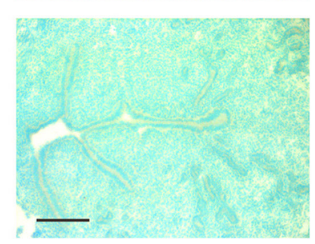

D5
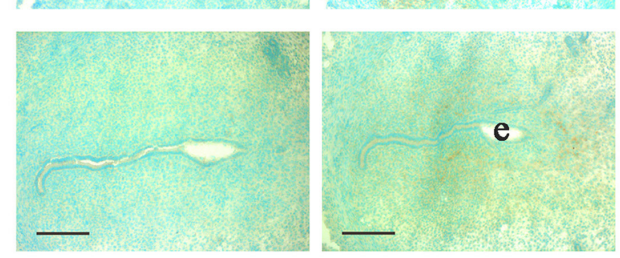

D7

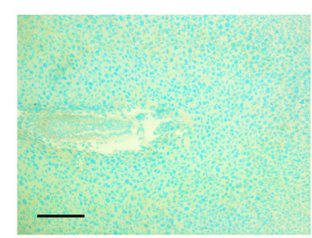

D8
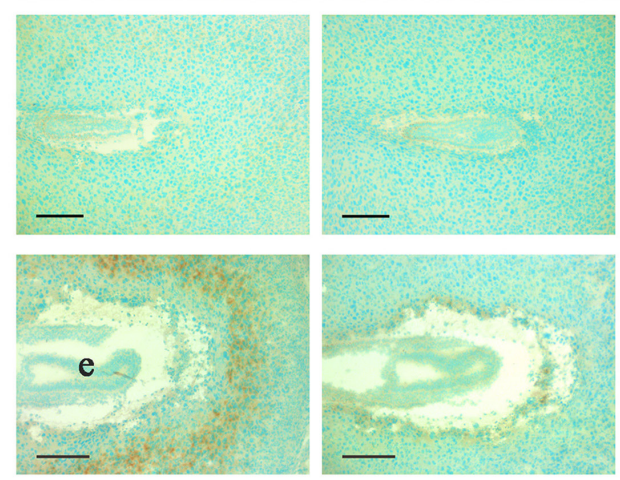
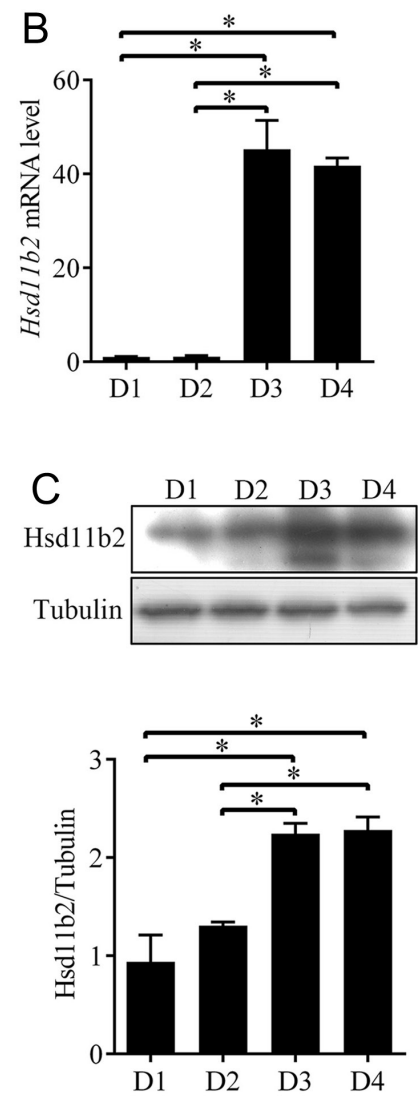

Figure 1

Spatiotemporal expression of Hsd11b1 and Hsd11b2 in mouse uteri during early pregnancy. (A) In situ hybridization of Hsd11b1 and Hsd11b2 mRNA expression in mouse uteri on days 1-8 of pregnancy. Hsd11b1 was mainly localized in secondary decidual zone on day 8 , whereas $H s d 11 b 2$ was highly expressed in stromal cells on days 3-4. s, stroma; le, luminal epithelium; e, embryo. Scale bar, $200 \mu \mathrm{m}$. (B) Real-time RT-PCR analysis of uterine Hsd11b2 mRNA levels on days $1(n=9), 2(n=9), 3(n=9)$ and $4(n=9)$ of pregnancy. (C) Western blot analysis of uterine Hsd11 b2 protein levels on days $1(n=6), 2(n=6)$, $3(n=6)$ and $4(n=6)$ of pregnancy. $* P<0.05$. A full colour version of this figure is available at https:// doi.org/10.1530/JOE-19-0349.
(Wang \& Dey 2006). Therefore, we explored whether there was a strong link between P4 and Hsd11b2. Treatment of ovariectomized mice with $\mathrm{P} 4$ for $12 \mathrm{~h}$ or $24 \mathrm{~h}$ caused a significant increase of Hsd11b2 mRNA and protein levels (Fig. 2A and B). To investigate whether P4 regulated the expression of Hsd11b2 through PGR, mice on day 3 of pregnancy were treated with RU486, an antagonist of PGR. Uterine Hsd11b2 mRNA levels were obviously down-regulated by RU486 for $24 \mathrm{~h}$ (Fig. 2C). To further evaluate the effects of $\mathrm{P} 4$, uterine stromal cells isolated from day 4 of pregnancy were treated with $\mathrm{P} 4$ or/and RU486 for $24 \mathrm{~h}$. Hsd11b2 expression was significantly induced by P4, which was obviously abrogated by RU486 (Fig. 2D). These results indicated that P4 regulated Hsd11b2 expression in a PGR-dependent manner.

\section{Regulation of Hsd11b2 by Ihh pathway of epithelial-stromal interaction}

Ihh, a target gene of P4, is highly expressed in the luminal and glandular epithelium on days 3 and 4 of gestation (Paria et al. 2001, Matsumoto et al. 2002, Takamoto et al. 2002, Lee et al. 2006). Ptc, the Ihh receptor, is also observed in uterine stromal cells on days 4-5 of pregnancy (Matsumoto et al. 2002), suggesting that Ihh, a diffusible factor from the epithelium, regulates stromal functions by paracrine mechanisms. We assumed that Ihh may regulate Hsd11b2 in the uterus. We found that Ihh was induced by $\mathrm{P} 4$ in ovariectomized mice (Fig. 3A). Since Sonic HH (Shh) and Desert HH (Dhh) in HH family also activate downstream hh signaling pathways, 

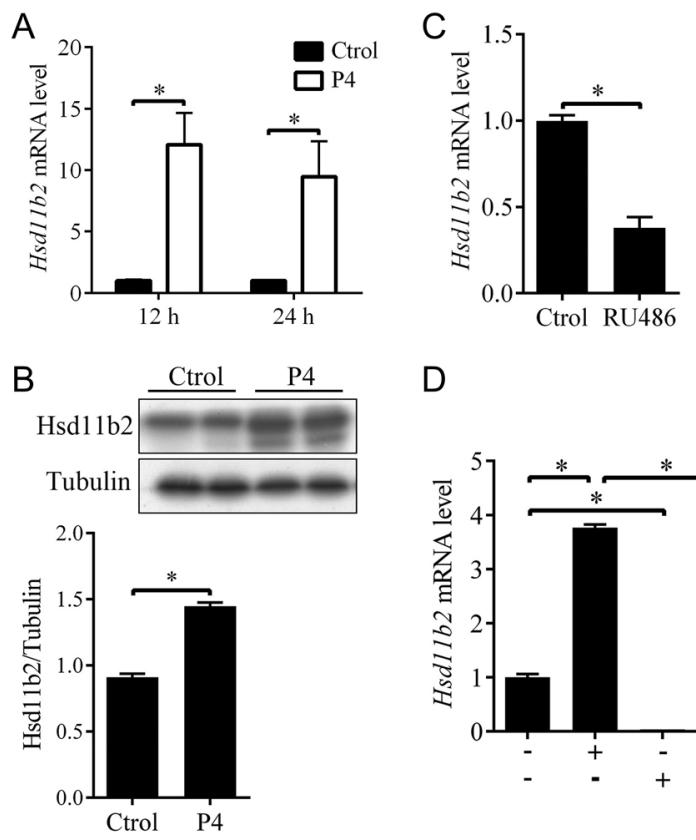

D

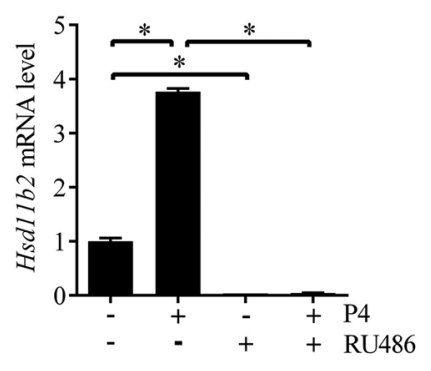

Figure 2

Effects of P4 on Hsd11b2 expression. (A) Uterine Hsd11b2 mRNA levels after ovariectomized mice received a single injection of oil or P4 for $12 \mathrm{~h}$ and $24 \mathrm{~h}$, respectively. $n=12$. (B) Western blot analysis of uterine Hsd $11 \mathrm{~b} 2$ protein levels $24 \mathrm{~h}$ after ovariectomized mice received a single injection of P4 (1 mg/mouse). $n=12$. (C) Real-time RT-PCR analysis of uterine Hsd11b2 mRNA levels after mice on day 3 were treated with RU486 for 24 h. $n=6$. (D) Real-time RT-PCR analysis of Hsd11b2 mRNA levels after stromal cells were treated with $1 \mu \mathrm{M}$ P4 or/and $1 \mu \mathrm{M}$ RU486 for 24 h. Ctrol, Control; P4, progesterone; RU486, a PGR antagonist. $* P<0.05$.

we examined whether they were regulated by progesterone. Our results showed that Shh expression was not detected by real-time RT-PCR, and Dhh expression remained unchangedby P4 treatment for $6 \mathrm{~h}$ (Fig. 3A). To study whether the Ihh signaling pathway was involved in the expression of hsd11b2, the uterine explants were treated with recombinant Ihh. The expression of Hsd11b2 was significantly induced by Ihh (Fig. 3B). Hsd11b2 expression in stromal cells was obviously suppressed by Cyclopamine, a specific antagonist of Smoothened in Ihh pathway (Fig. 3C). Furthermore, stromal Hsd11b2 expression was significantly stimulated by purmorphamine, an agonist of Smoothened (Fig. 3D and E). These results indicated that the expression of Hsd11b2 was regulated by Ihh signaling.

Although mRNA levels of Gli1, Gli2 and Gli3 increased during preimplantation period, the levels of Gli1 were much higher than Gli2 and Gli3, especially on days 3 and 4 (Fig. 4A). Furthermore, only Gli1 was induced by Ihh and Purmorphamine in vitro (Fig. 4B and C). The expression of $H s d 11 b 2$ was obviously downregulated after stromal cells were treated with GANT61, an inhibition of
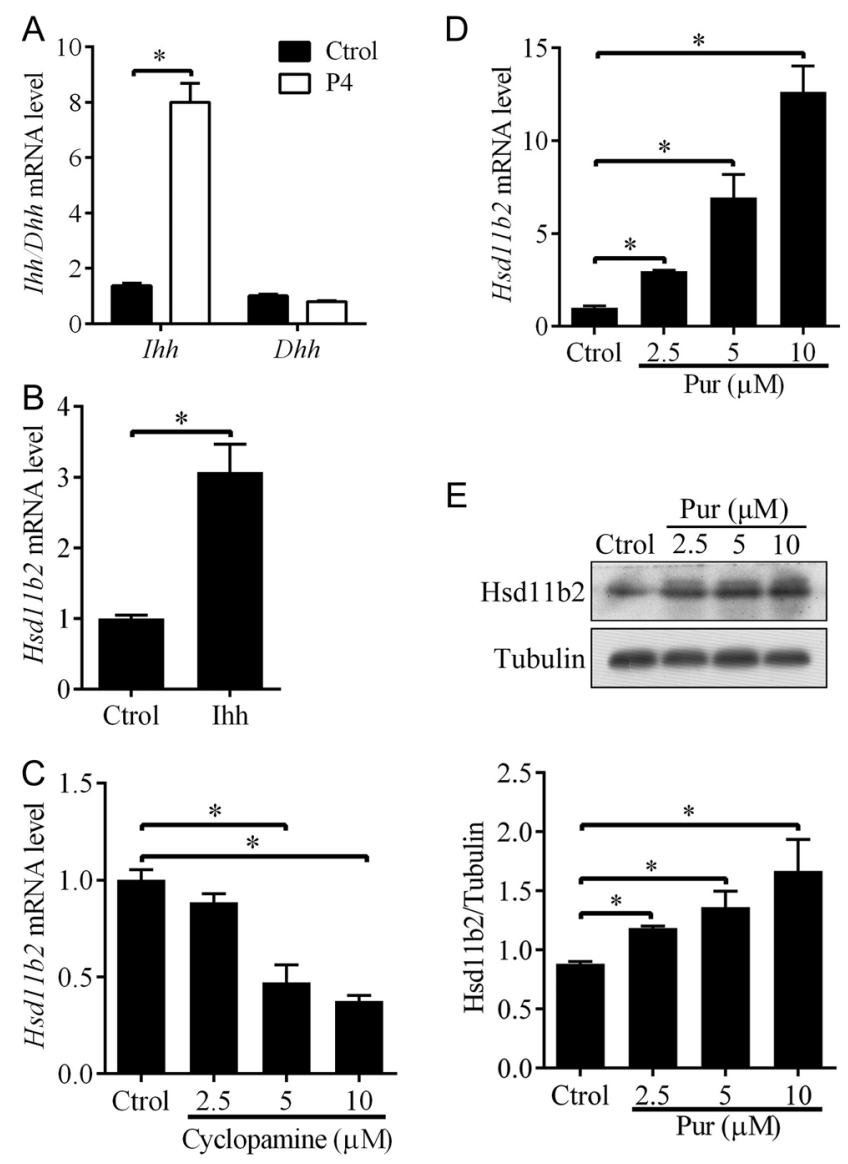

\section{Figure 3}

Hsd 11 b2 regulation by P4 through the Ihh pathway. (A) Uterine Ihh and Dhh mRNA levels after ovariectomized mice received a single injection of oil or $1 \mathrm{mg} / \mathrm{mouse}$ P4 for 6 h. $n=6$. (B) The effect of recombinant Ihh on uterine $\mathrm{Hsd} 11 \mathrm{~b} 2 \mathrm{mRNA}$ levels in explant cultures. Longitudinally split uterine pieces devoid of luminal epithelium were cultured for $48 \mathrm{~h}$ in the absence or presence of $\mathrm{lhh}(2 \mu \mathrm{g} / \mathrm{mL}) . n=6$. (C) Real-time RT-PCR analysis of Hsd11b2 mRNA levels after stromal cells were treated with different doses of Cyclopamine for $24 \mathrm{~h}$. Cyclopamine, a Smoothened antagonist in Ihh pathway. (D) Real-time RT-PCR analysis of Hsd11b2 mRNA after stromal cells were treated with different doses of Pur for $24 \mathrm{~h}$. (E) Western blot analysis of $\mathrm{Hsd} 11 \mathrm{~b} 2$ protein after stromal cells were treated with different doses of Pur for $24 \mathrm{~h}$. Pur, Purmorphamine, a Smoothened agonist. $* P<0.05$.

Ihh pathway for Gli1/2 (Fig. 4D). Therefore, Gli1 was the dominant form for Ihh regulation of Hsd11b2.

\section{Effects of P4 on uterine Cort}

To further analyze the role of Hsd11b2 on uterine GC balance, we compared Cort levels in uterine lumen fluid between days 2 and 3 of pregnancy. Cort levels on day 3 were significantly lower than those on day 2 (Fig. 5A). Considering P4 upregulation on Hsd11b2, we anticipated that P4 may have the ability to downregulate Cort level 
A

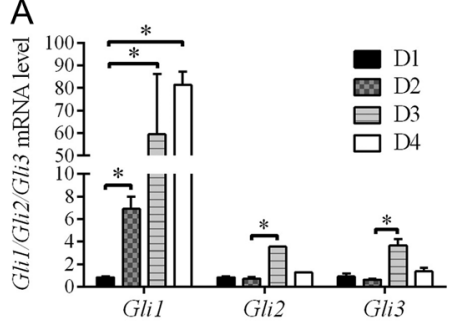

C

D

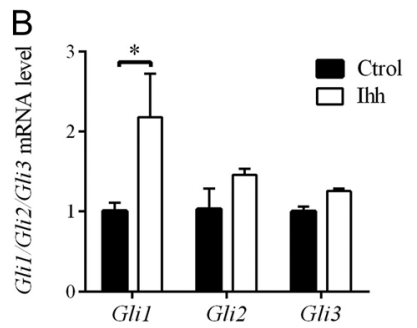

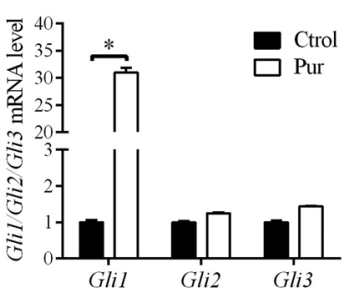

A

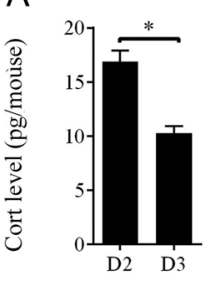

C

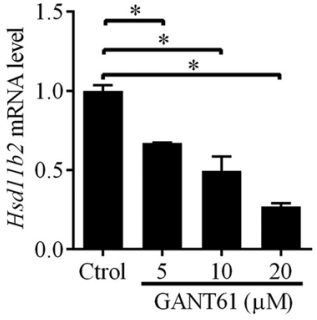

Figure 4

Expression levels of Gli1, Gli2 and Gli3. (A) Real-time RT-PCR analysis of Gli1, Gli2 and Gli3 mRNA levels on days 1-4 of pregnancy. (B) The effect of recombinant Ihh on uterine Gli1, Gli2 and Gli3 mRNA levels in explant cultures. (C) Real-time RT-PCR analysis of Hsd11b2 mRNA levels after stromal cells were treated with $2.5 \mu \mathrm{M}$ Pur for $24 \mathrm{~h}$. Pur, Purmorphamine. (D) Real-time RT-PCR analysis of Hsd11b2 mRNA levels after stromal cells were treated with different doses of GANT61 for $24 \mathrm{~h}$. GANT61, an inhibitor for Gli1 and Gli2. ${ }^{*} P<0.05$.

in uterine fluid by promoting expression of Hsd11b2. To confirm, we injected exogenous Cort into ovariectomized mice and found that the concentration of Cort in the uterine lumen was nearly ten-fold higher than that in the control group. This increase of Cort was abrogated by pretreatment with $\mathrm{P} 412 \mathrm{~h}$ before Cort injection (Fig. 5B). Meanwhile, we also examined Cort levels in serum. We observed that serum levels of Cort were significantly higher in the Cort-treated group than in the untreated group (Fig. 5C). However, the serum levels of Cort were not significantly different between the P4-pretreated group and the untreated group after ovariectomized mice received a single injection of Cort (Fig. 5C), suggesting that P4 only downregulated uterine Cort but had no effect on systemic Cort. Meanwhile, Hsd11b2 expression was not only increased by $\mathrm{P} 4$ pretreatment, but also by treatment of both $\mathrm{P} 4$ and Cort (Fig. 5D). However, uterine $H s d 11 b 1$ expression remained relatively stable after ovariectomized mice were treated by P4 or Cort (Fig. 5E).

\section{Effects of Cort and SPS on uterine Hsd11b2}

Because GCs are mainly involved in stress responses, we analyzed whether Hsd11b2 expression was affected by SPS. Serum levels of Cort were significantly increased
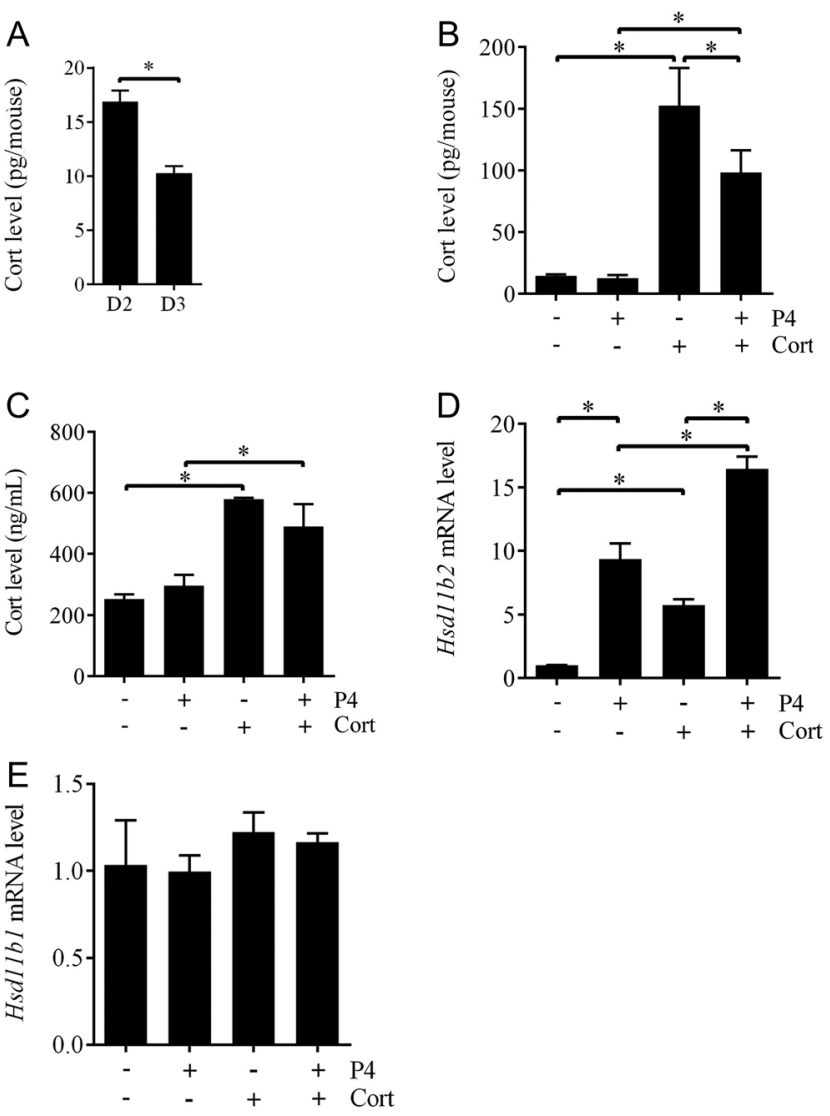

Figure 5

Effects of P4 on uterine Cort concentration. (A) The levels of Cort in the fluid of uterine lumen on days $2(n=10)$ and $3(n=9)$. (B) Cort levels in uterine fluid after ovariectomized mice received a single injection of P4 or Cort. $n=24$. (C) Serum levels of Cort after ovariectomized mice received a single injection of P4 or Cort. (D) Uterine Hsd11b2 mRNA level after ovariectomized mice received a single injection of P4 or Cort. (E) Uterine Hsd11b1 mRNA level after ovariectomized mice received a single injection of P4 or Cort. Cort, corticosterone.

$1 \mathrm{~h}$ after ovariectomized mice underwent SPS (Fig. 6A). In order to verify that the effect of SPS on Hsd11b2 is mainly played by Cort, a single injection of exogenous Cort ( $1 \mathrm{mg} /$ mouse) of ovariectomized mice also caused a sharp increase of serum Cort level in $1 \mathrm{~h}$ (Fig. 6B). Uterine Hsd11b2 expression was significantly increased $6 \mathrm{~h}$ after SPS (Fig. 6C). Injection of exogenous Cort also stimulated uterine $H s d 11 b 2$ mRNA expression (Fig. 6D). Moreover, $H s d 11 b 2$ mRNA levels were significantly increased when cultured stromal cells were treated with $1 \mu \mathrm{M}$ or $10 \mu \mathrm{M}$ Cort for $24 \mathrm{~h}$ (Fig. 6E).

\section{Effects of Cort on embryo development in vitro}

Our data showed that exogenous injection of Cort could induce an increase of Cort levels in the 

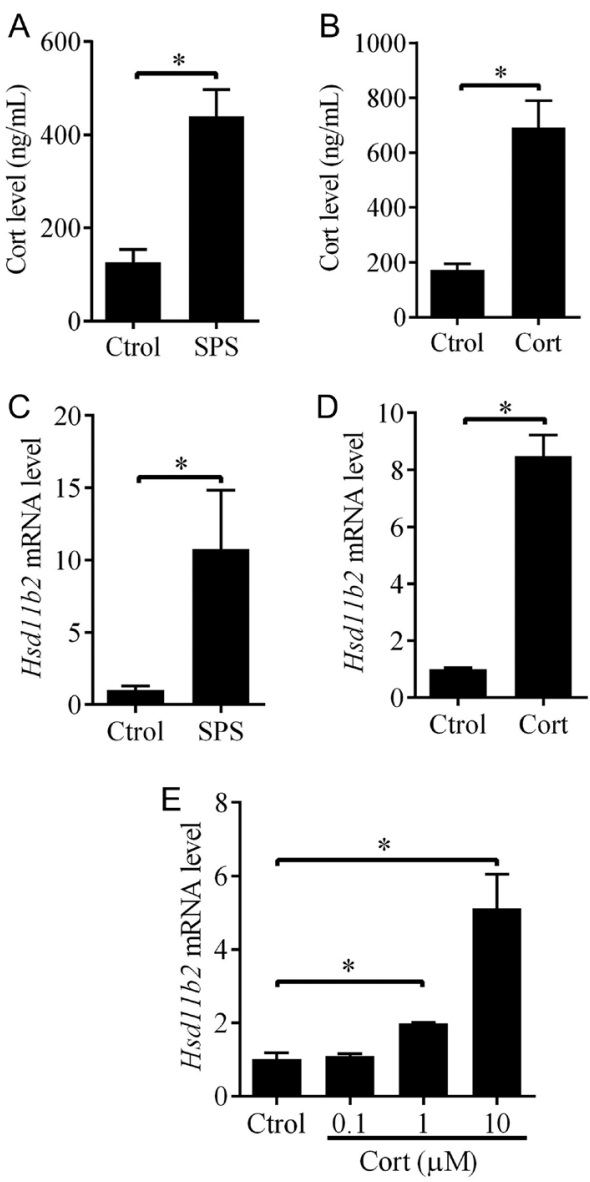

\section{Figure 6}

Effects of SPS and Cort on Cort level. (A) The serum levels of Cort $1 \mathrm{~h}$ after ovariectomized mice underwent SPS. $n=9$. (B) The serum levels of Cort $1 \mathrm{~h}$ after ovariectomized mice received a single injection of exogenous Cort. $n=9$. (C) Uterine Hsd11b2 mRNA levels $6 \mathrm{~h}$ after ovariectomized mice received a SPS. $n=9$. (D) Uterine Hsd11b2 mRNA levels $6 \mathrm{~h}$ after ovariectomized mice received a single injection of exogenous Cort for $6 \mathrm{~h}$. $n=9$. (E) The Hsd11b2 mRNA levels after stromal cells were treated with different concentrations of Cort for $24 \mathrm{~h}$.

uterine lumen (Fig. 5B). Therefore, we evaluated the effect of Cort on the development of mouse embryos in vitro. After two-cell mouse embryos were treated with different concentrations of Cort, $100 \mu \mathrm{M}$ Cort reduced the rate of blastocyst formation, but 1 or $10 \mu \mathrm{M}$ Cort had no obvious effects (Fig. 7A). Only $100 \mu \mathrm{M}$ Cort significantly reduced the rate of embryo hatching (Fig. 7B). To further analyze the potential effect of Cort on embryo development, we counted the number of inner cell mass cells shown by immunofluorescence with anti-Oct4 antibody. Our analysis showed that the number of inner cell mass cells significantly decreased after two-cell embryos were cultured with $0.1,1$ or $10 \mu \mathrm{M}$ Cort compared to the control group (Fig. 7C).

\section{Discussion}

In our study, Hsd11b1 is mainly localized in the endometrial secondary decidual zone on day 8 of pregnancy. A previous study reported that Hsd11b1 mRNA and protein levels progressively increased from day 5 to the last day of pregnancy in mouse uteri (Damiani et al. 2017). Data from uterine GR KO mice indicates that the GR-mediated GC signaling pathway is necessary for embryo implantation and decidualization (Whirledge et al. 2015). In the mouse, GR stimulates the induction of WNT4, a key regulator of progesterone signaling during decidualization (Franco et al. 2011). Indeed, HSD11B1 is expressed at its highest levels in the human endometrium decidua (Michael \& Papageorghiou 2008). In vitro decidualization in humans induces strong HSD11B1 expression (105-fold) (Takano et al. 2007). These data suggest that local Cort generated by Hsd11b1 likely plays an important role for the process of decidualization.

In our study, Hsd11b2 mRNA and protein levels have an obvious increase from day 3 to 4 of pregnancy. Because the Hsd11b2 expression pattern is matched with a high level of $\mathrm{P} 4$ during preimplantation (Egashira \& Hirota 2013), we further showed that Hsd11b2 expression is regulated by Ihh signaling. P4 stimulates stromal Hsd11b2 expression through secreted Ihh from the luminal epithelium via Smoothened and Gli1. Ihh is strongly expressed in the uterine epithelium of the preimplantation mouse uterus and regulated by progesterone (Matsumoto et al. 2002, Takamoto et al. 2002). Embryo implantation fails in mice with uterus-specific Ihh deletion (Lee et al. 2006). The loss of epithelial Ihh also results in aberrant gene expression in the stroma (Kurihara et al. 2007, Bhurke et al. 2016).

In the Ihh pathway, downstream transcription factors Gli1 and Gli2 of Smoothened are upregulated from day 3 of pregnancy (Matsumoto et al. 2002). In both human primary cytotrophoblasts and trophoblast-like BeWo cells, HSD11B2 expression is regulated by SHH/GLI2 signaling (Zhu et al. 2016). In our study, Shh expression in the mouse uterus during preimplantation is under the detectable range by real-time RT-PCR and is not regulated by P4. Furthermore, P4 has no effect on Dhh expression, which is expressed at a low level. Our data suggest that Ihh is the dominant form in mediating Hsd11b2 expression.

Although the abundant expression of placental Hsd11b2 has been believed to function mainly as a barrier for maternal GCs (Zhu et al. 2019), the expression and function of Hsd11b2 have not been reported during early pregnancy in mice. Recent data showed that high 


\begin{tabular}{l|l|l|r|r|}
$\begin{array}{l}\text { Journal of } \\
\text { Endocrinology }\end{array}$ & H-T Zheng et al. & $\begin{array}{l}\text { Hsd11b2 regulation in mouse } \\
\text { uterus }\end{array}$ & $\mathbf{2 4 4 : 1}$ & $\mathbf{1 8 5}$ \\
\hline
\end{tabular}
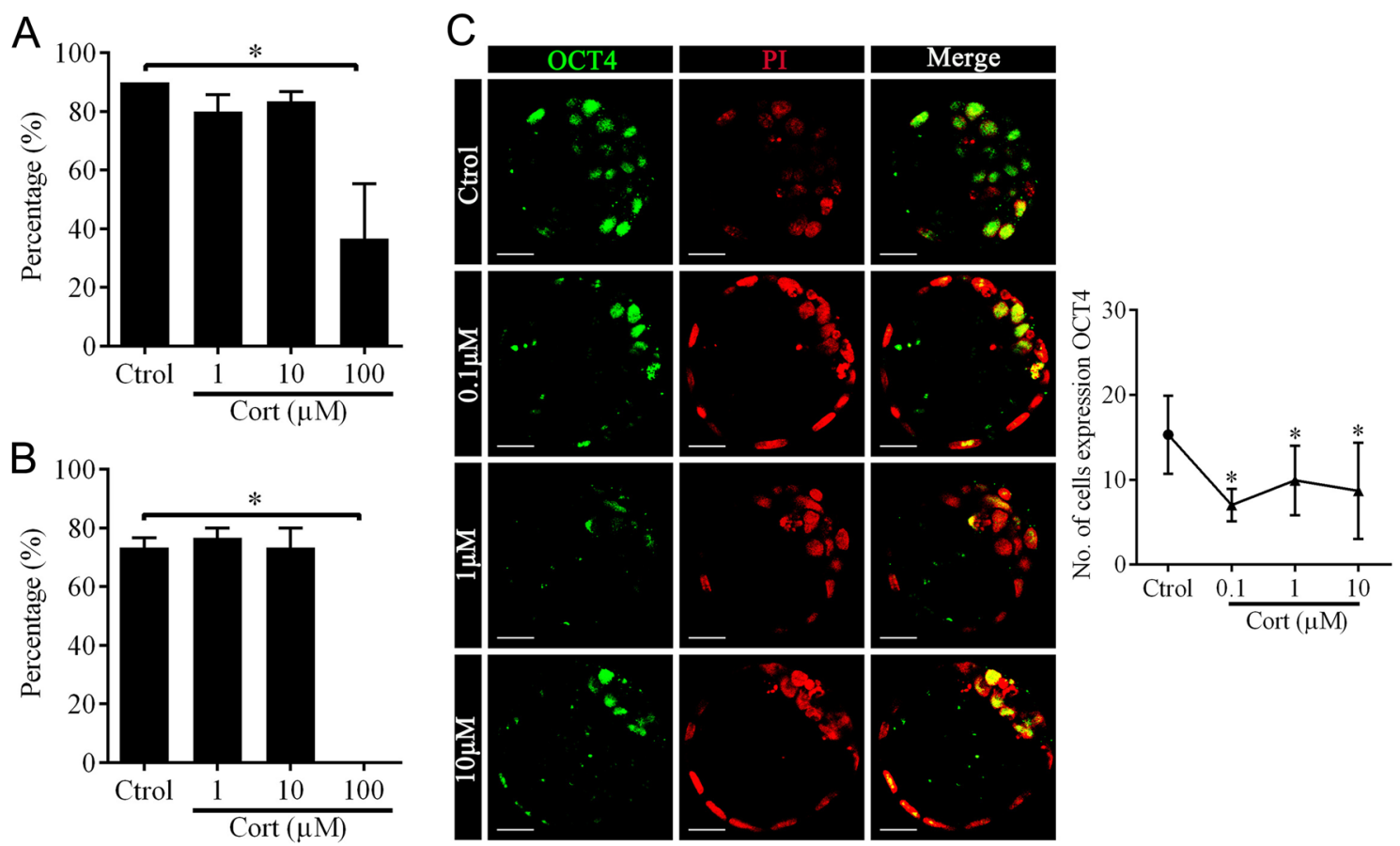

Figure 7

Effects of Cort on the development of mouse embryos in vitro. (A) The rate of blastocyst formation after two-cell embryos were cultured with 0 ( $n=78$ ), $1(n=98), 10(n=86)$ or $100 \mu \mathrm{M}(n=90)$ Cort to blastocyst stage. (B) The rate of blastocyst hatching after two-cell embryos were cultured with different concentrations of Cort to blastocyst stage. (C) The number of inner cell mass expressing Oct4 after two-cell embryos were cultured with 0 ( $n=61$ ), $0.1(n=56), 1(n=51)$ or $10 \mu \mathrm{M}(n=43)$ of Cort to blastocyst stage. A full colour version of this figure is available at https://doi.org/10.1530/JOE-19-0349.

levels of Cort are detrimental for mouse receptivity and decidualization (Zhao et al. 2013, Li et al. 2018). The high levels of endometrial Hsd11b2 before implantation suggest that the uterus provides an environment of lowlevel Cort for embryo implantation. Isolated endometrial stromal cells and embryo are exposed to physiological concentrations $\left(1 \times 10^{-7} \mathrm{M}\right.$, Gong et al. 2015) and supraconcentrations of Cort $\left(1 \times 10^{-6} \mathrm{M}\right.$ and $\left.1 \times 10^{-5} \mathrm{M}\right)$. The results show that supra-concentrations Cort promote the expression of $H s d 11 b 2$ mRNA levels in stromal cells. This suggests that endometrial stromal cells provide a potential for reducing high concentrations of Cort by Hsd11b2. Based on our date and previous studies by other groups, mouse embryos are resistant to high levels of Cort, considering the rate of blastocyst formation and hatching (Zhao et al. 2013, Li et al. 2018). However, inner cell mass development is sensitive to Cort exposure, unlike blastocyst formation and hatching, as the number of inner cell mass cells is significantly reduced by a lower concentration of Cort.

Because mouse preimplantation embryos are sensitive to Cort, the high level of Hsd11b2 in the uterus on days 2 and 3 provides a low-level Cort environment for preimplantation development of mouse embryos. Our studies showed that the concentration of Cort in the uterine lumen fluid is significantly reduced by P4-induced Hsd11b2 expression. Additionally, the stimulated increase of Hsd11b2 levels by SPS or Cort injection triggers protective mechanisms to prevent damage to embryos by high levels of maternal Cort. The high expression of placental Hsd11b2 acts as a GC barrier to protect the fetus from excessive maternal Cort exposure (Seckl \& Walker 2001, Zhu et al. 2019). It is possible that endometrial Hsd11b2 regulated by $\mathrm{P} 4$ provides a suitable GC environment in the uterine lumen for preimplantation development. HSD11B2 is expressed in normal endometria during the menstrual cycle at higher levels than HSD11B1 (McDonald et al. 2006), suggesting the same mechanism may also work in human reproduction.

In conclusion, our data showed that high levels of uterine Hsd11b2 expression during preimplantation is regulated by $\mathrm{P} 4$ via Ihh signaling pathway. The strong expression of Hsd11b2 should provide a suitable Cort environment during preimplantation for mouse embryos. 


\section{Declaration of interest}

The authors declare that there is no conflict of interest that could be perceived as prejudicing the impartiality of the research reported.

\section{Funding}

This work was supported by National Key Research and Development Program of China (2018YFC1004403) and National Natural Science Foundation of China (31471397, 31272263 and 31671563).

\section{Author contribution statement}

H T Z and Z M Y designed experiments; T F, Z S Y, and H T Z performed research and acquired data; $T F, H Y Z$, and $H T Z$ analyzed data; $T H Z, Z S Y$, and $Z M Y$ interpreted data; $H$ T Z, H Y Z and Z M Y wrote the paper and revised it; all authors gave the final approve of the version to be published.

\section{References}

Beitins IZ, Bayard F, Ances IG, Kowarski A \& Migeon CJ 1973 The metabolic clearance rate, blood production, interconversion and transplacental passage of cortisol and cortisone in pregnancy near term. Pediatric Research 7 509-519. (https://doi. org/10.1203/00006450-197305000-00004)

Bhurke AS, Bagchi IC \& Bagchi MK 2016 Progesterone-regulated endometrial factors controlling implantation. American Journal of Reproductive Immunology 75 237-245. (https://doi.org/10.1111/ aji.12473)

Boomsma CM, Keay SD \& Macklon NS 2012 Peri-implantation glucocorticoid administration for assisted reproductive technology cycles. Cochrane Database of Systematic Reviews 6 CD005996. (https:// doi.org/10.1002/14651858.CD005996.pub3)

Cha J, Sun X \& Dey SK 2012 Mechanisms of implantation: strategies for successful pregnancy. Nature Medicine 18 1754-1767. (https://doi. org/10.1038/nm.3012)

Cheon YP, Li Q, Xu X, DeMayo FJ, Bagchi IC \& Bagchi MK 2002 A genomic approach to identify novel progesterone receptor regulated pathways in the uterus during implantation. Molecular Endocrinology 16 2853-2871. (https://doi.org/10.1210/me.2002-0270)

Damiani F, Makieva S, Rinaldi SF, Hua L, Marcolongo P, Petraglia F \& Norman JE 2017 11ß-Hydroxysteroid dehydrogenase type 1 and pregnancy: role in the timing of labour onset and in myometrial contraction. Molecular and Cellular Endocrinology 447 79-86. (https:// doi.org/10.1016/j.mce.2017.02.034)

Deslauriers J, Toth M, Der-Avakian A \& Risbrough VB 2018 Current status of animal models of posttraumatic stress disorder: behavioral and biological phenotypes, and future challenges in improving translation. Biological Psychiatry 83 895-907. (https://doi. org/10.1016/j.biopsych.2017.11.019)

Dey SK, Lim H, Das SK, Reese J, Paria BC, Daikoku T \& Wang H 2004 Molecular cues to implantation. Endocrine Reviews 25 341-373. (https://doi.org/10.1210/er.2003-0020)

Ding NZ, Qi QR, Gu XW, Zuo RJ, Liu J \& Yang ZM 2018 De novo synthesis of sphingolipids is essential for decidualization in mice. Theriogenology 106 227-236. (https://doi.org/10.1016/j. theriogenology.2017.09.036)

Dy J, Guan H, Sampath-Kumar R, Richardson BS \& Yang K 2008 Placental $11 \beta$-hydroxysteroid dehydrogenase type 2 is reduced in pregnancies complicated with idiopathic intrauterine growth restriction: evidence that this is associated with an attenuated ratio of cortisone to cortisol in the umbilical artery. Placenta 29 193-200. (https://doi. org/10.1016/i.placenta.2007.10.010)

Egashira M \& Hirota Y 2013 Uterine receptivity and embryo-uterine interactions in embryo implantation: lessons from mice. Reproductive Medicine and Biology 12 127-132. (https://doi.org/10.1007/s12522013-0153-1)

Franco HL, Dai D, Lee KY, Rubel CA, Roop D, Boerboom D, Jeong JW, Lydon JP, Bagchi IC, Bagchi MK, et al. 2011 WNT4 is a key regulator of normal postnatal uterine development and progesterone signaling during embryo implantation and decidualization in the mouse. FASEB Journal 25 1176-1187. (https://doi.org/10.1096/fj.10-175349)

Franco HL, Rubel CA, Large MJ, Wetendorf M, Fernandez-Valdivia R, Jeong JW, Spencer TE, Behringer RR, Lydon JP \& Demayo FJ 2012 Epithelial progesterone receptor exhibits pleiotropic roles in uterine development and function. FASEB Journal 26 1218-1227. (https://doi. org/10.1096/fj.11-193334)

Gong S, Miao YL, Jiao GZ, Sun MJ, Li H, Lin J, Luo MJ \& Tan JH 2015 Dynamics and correlation of serum cortisol and corticosterone under different physiological or stressful conditions in mice. PLOS ONE 10 e0117503. (https://doi.org/10.1371/journal.pone.0117503)

Jafari Z, Faraji J, Mirza Agha B, Metz GAS, Kolb BE \& Mohajerani MH 2017 The adverse effects of auditory stress on mouse uterus receptivity and behaviour. Scientific Reports 7 4720. (https://doi. org/10.1038/s41598-017-04943-8)

Kurihara I, Lee DK, Petit FG, Jeong J, Lee K, Lydon JP, DeMayo FJ, Tsai MJ $\&$ Tsai SY 2007 COUP-TFII mediates progesterone regulation of uterine implantation by controlling ER activity. PLoS Genetics 3 e102. (https://doi.org/10.1371/journal.pgen.0030102)

Lee K, Jeong J, Kwak I, Yu CT, Lanske B, Soegiarto DW, Toftgard R, Tsai MJ, Tsai S, Lydon JP, et al. 2006 Indian hedgehog is a major mediator of progesterone signaling in the mouse uterus. Nature Genetics 38 1204-1209. (https://doi.org/10.1038/ng1874)

Lei W, Feng XH, Deng WB, Ni H, Zhang ZR, Jia B, Yang XL, Wang TS, Liu JL, Su RW, et al. 2012 Progesterone and DNA damage encourage uterine cell proliferation and decidualization through up-regulating ribonucleotide reductase 2 expression during early pregnancy in mice. Journal of Biological Chemistry 287 15174-15192. (https://doi. org/10.1074/jbc.M111.308023)

Li QN, Li L, Hou G, Wang ZB, Hou Y, Liu ZH, Schatten H \& Sun QY 2018 Glucocorticoid exposure affects female fertility by exerting its effect on the uterus but not on the oocyte: lessons from a hypercortisolism mouse model. Human Reproduction 33 2285-2294. (https://doi. org/10.1093/humrep/dey322)

Lydon JP, DeMayo FJ, Funk CR, Mani SK, Hughes AR, Montgomery CA, Shyamala G, Conneely OM \& O'Malley BW 1995 Mice lacking progesterone receptor exhibit pleiotropic reproductive abnormalities. Genes and Development 9 2266-2278. (https://doi.org/10.1101/ gad.9.18.2266)

Matsumoto H, Zhao X, Das SK, Hogan BL \& Dey SK 2002 Indian hedgehog as a progesterone-responsive factor mediating epithelialmesenchymal interactions in the mouse uterus. Developmental Biology 245 280-290. (https://doi.org/10.1006/dbio.2002.0645)

Mazumdar T, DeVecchio J, Shi T, Jones J, Agyeman A \& Houghton JA 2011 Hedgehog signaling drives cellular survival in human colon carcinoma cells. Cancer Research 71 1092-1102. (https://doi. org/10.1158/0008-5472.CAN-10-2315)

McDonald SE, Henderson TA, Gomez-Sanchez CE, Critchley HOD \& Mason JI 2006 11beta-Hydroxysteroid dehydrogenases in human endometrium. Molecular and Cellular Endocrinology 248 72-78. (https://doi.org/10.1016/j.mce.2005.12.010)

McMahon AP 2000 More surprises in the Hedgehog signaling pathway. Cell 100 185-188. (https://doi.org/10.1016/s0092-8674(00)81555-x)

Michael AE \& Papageorghiou AT 2008 Potential significance of physiological and pharmacological glucocorticoids in early pregnancy. Human Reproduction Update 14 497-517. (https://doi. org/10.1093/humupd/dmn021) https://joe.bioscientifica.com https://doi.org/10.1530/JOE-19-0349 (c) 2020 Society for Endocrinology Published by Bioscientifica Ltd. Printed in Great Britain 
Paria BC, Ma W, Tan J, Raja S, Das SK, Dey SK \& Hogan BL 2001 Cellular and molecular responses of the uterus to embryo implantation can be elicited by locally applied growth factors. PNAS 98 1047-1052. (https://doi.org/10.1073/pnas.98.3.1047)

Robertson SA, Jin M, Yu D, Moldenhauer LM, Davies MJ, Hull ML \& Norman RJ 2016 Corticosteroid therapy in assisted reproduction - immune suppression is a faulty premise. Human Reproduction $\mathbf{3 1}$ 2164-2173. (https://doi.org/10.1093/humrep/dew186)

Sandeep TC \& Walker BR 2001 Pathophysiology of modulation of local glucocorticoid levels by 11beta-hydroxysteroid dehydrogenases. Trends in Endocrinology and Metabolism 12 446-453. (https://doi org/10.1016/S1043-2760(01)00499-4)

Seckl JR \& Meaney MJ 2004 Glucocorticoid programming. Annals of the New York Academy of Sciences 1032 63-84. (https://doi.org/10.1196/ annals.1314.006)

Seckl JR \& Walker BR 2001 Minireview: 11ß-hydroxysteroid dehydrogenase type 1 - a tissue-specific amplifier of glucocorticoid action. Endocrinology 142 1371-1376. (https://doi.org/10.1210/endo.142.4.8114)

Takamoto N, Zhao B, Tsai SY \& DeMayo FJ 2002 Identification of Indian hedgehog as a progesterone-responsive gene in the murine uterus. Molecular Endocrinology 16 2338-2348. (https://doi.org/10.1210/ me.2001-0154)

Takano M, Lu Z, Goto T, Fusi L, Higham J, Francis J, Withey A, Hardt J, Cloke B, Stavropoulou AV, et al. 2007 Transcriptional cross talk between the forkhead transcription factor forkhead box O1A and the progesterone receptor coordinates cell cycle regulation and differentiation in human endometrial stromal cells. Molecular Endocrinology 21 2334-2349. (https://doi.org/10.1210/me.2007-0058)

Togher KL, Togher KL, O'Keeffe MM, O'Keeffe MM, Khashan AS, Khashan AS, Gutierrez H, Gutierrez H, Kenny LC, Kenny LC, et al. 2014 Epigenetic regulation of the placental HSD11B2 barrier and its role as a critical regulator of fetal development. Epigenetics 9 816-822. (https://doi.org/10.4161/epi.28703)

Tu Z, Ran H, Zhang S, Xia G, Wang B \& Wang H 2014 Molecular determinants of uterine receptivity. International Journal of Developmental Biology 58 147-154. (https://doi.org/10.1387/ ijdb.130345wh)

Wang H \& Dey SK 2006 Roadmap to embryo implantation: clues from mouse models. Nature Reviews: Genetics 7 185-199. (https://doi. org/10.1038/nrg1808)

Whirledge SD, Oakley RH, Myers PH, Lydon JP, DeMayo F \& Cidlowski JA 2015 Uterine glucocorticoid receptors are critical for fertility in mice through control of embryo implantation and decidualization. PNAS 112 15166-15171. (https://doi.org/10.1073/pnas.1508056112)

Wu X, Walker J, Zhang J, Ding S \& Schultz PG 2004 Purmorphamine induces osteogenesis by activation of the hedgehog signaling pathway. Chemistry and Biology 11 1229-1238. (https://doi. org/10.1016/j.chembiol.2004.06.010)

Zhao LH, Cui XZ, Yuan HJ, Liang B, Zheng LL, Liu YX, Luo MJ \& Tan JH 2013 Restraint stress inhibits mouse implantation: temporal window and the involvement of HB-EGF, estrogen and progesterone. PLoS ONE $\mathbf{8}$ e80472. (https://doi.org/10.1371/ journal.pone.0080472)

Zhu H, Zou C, Fan X, Xiong W, Tang L, Wu X \& Tang C 2016 Up-regulation of 11 beta-hydroxysteroid dehydrogenase type 2 expression by hedgehog ligand contributes to the conversion of cortisol into cortisone. Endocrinology 157 3529-3539. (https://doi. org/10.1210/en.2016-1286)

Zhu P, Wang W, Zuo R \& Sun K 2019 Mechanisms for establishment of the placental glucocorticoid barrier, a guard for life. Cellular and Molecular Life Sciences 76 13-26. (https://doi.org/10.1007/s00018-0182918-5)

Received in final form 7 October 2019

Accepted 10 October 2019

Accepted Manuscript published online 10 October 2019 (c) 2020 Society for Endocrinology Published by Bioscientifica Ltd. 